\title{
Study the relationship between nasal polyps, platelet count, mean platelet volume, neutrophil/lymphocyte ratio in patients attending otolaryngology OPD in a tertiary care teaching hospital, West Bengal
}

\author{
Manuprita Sharma ${ }^{1}$, Santosh Raman $^{2}$, Bidhan Ray ${ }^{1}$, Rupali Verma Bagga ${ }^{3}$, \\ Ramesh Kumar Sahu ${ }^{4}$, Sujoy De
}

\begin{abstract}
${ }^{1}$ Department of ENT, ${ }^{3}$ Department of Community Medicine, ${ }^{4}$ Department of Radiodiagnosis, ${ }^{5}$ Department of Pathology, ICARE Institute of Medical Sciences and Research, Banbishnupur, Purba Medinipur, Haldia, West Bengal, India

${ }^{2}$ Department of ENT, Mata Gujri Memorial Medical College, Purabbali, Dinajpur Road, Kishanganj, Bihar, India
\end{abstract}

Received: 16 January 2017

Accepted: 01 February 2017

\section{*Correspondence:}

Dr. Manuprita Sharma,

E-mail: manupritsharma@gmail.com

Copyright: () the author(s), publisher and licensee Medip Academy. This is an open-access article distributed under the terms of the Creative Commons Attribution Non-Commercial License, which permits unrestricted non-commercial use, distribution, and reproduction in any medium, provided the original work is properly cited.

\section{ABSTRACT}

Background: Nasal obstruction is a common cause of marked nasal septal deviation. It is related strongly with hypoxia. Hypoxic conditions increase mean platelet volume levels. Many studies in literature point out that inflammation related to nasal polyp is mostly dependent on eosinophils and their inflammatory products. Beside eosinophils, platelets may have a role in nasal polyp development. Platelets are involved in hemostasis, tissue repairing and inflammation. Recently, mean platelet volume (MPV) was recognized as a simple inflammatory marker in the inflammatory disease. This study investigated the relationship of nasal polyps with MPV (mean platelet volume), platelet count and NLR (neutrophil to lymphocyte ratio).

Methods: The cross-sectional observational study we investigated CBC (complete blood count) parameters of the patients that consulted ENT clinic in a tertiary care teaching hospital, Haldia because of nasal polyp. About 76 patients and 42 controls were included in this study. In all groups, WBC (white blood cell count), RBC (red blood cell count), RDW (red cell distribution width), platelet count, MPV, PDW (platelet distribution width) and NLR parameters from CBC (complete blood count) were compared between patients and controls.

Results: Mean WBC values were $6.89 \pm 1.33 \times 103 / \mu \mathrm{L}$ in patients with NPs, vs. $7.11 \pm 2.32 \times 103 / \mu \mathrm{L}$ in the control group. Mean haemoglobin $(\mathrm{Hb})$ values were $13.19 \pm 1.34 \mathrm{~g} / \mathrm{dL}$ in patients with NPs, vs. $14.1 \pm 1.67 \mathrm{~g} / \mathrm{dl}$ in the control group. Mean MPV values were $9.11 \pm 1.08 \mathrm{fL}$ in patients with NPs, vs. $8.32 \pm 0.53 \mathrm{fL}$ in the control group. Mean PLT values were $232.38 \pm 39.97 \times 103 / \mu \mathrm{L}$ in patients with $\mathrm{NPs}$, vs. $271.44 \pm 45.14 \times 103$ in the control group. MPV was higher in nasal polyp patients, whereas platelet count was higher in controls. The difference was significant for the mean absolute neutrophil, platelet count, and lymphocyte counts, NLR, PDW and MPV values between the study group and the control group.

Conclusions: Platelet count and NLR were significantly lower in patients than the controls, whereas MPV was significantly higher in nasal polyp patients.

Keywords: Nasal polyps, Controls, Mean platelet volume, Platelet count, White blood cell count, Neutrophil-tolymphocyte ratio 


\section{INTRODUCTION}

Nasal polyps (NPs) are a benign mucosal disorder as a result of mucosal inflammation that originates from any portion of the nasal mucosa or paranasal sinuses. ${ }^{1}$ It is the most common non-neoplastic lesion in the nasal cavity. It also is a very common cause of chronic nasal obstruction. $^{2}$ They are characterized by chronic mucosal inflammation of the nose and paranasal sinuses. They are observed twice as much in men than in women and incidence in the population is about $1-4 \%$. $^{3}$ The polyps are found in $36 \%$ of patients with aspirin intolerance, in $7 \%$ of those with asthma, in $20 \%$ of those with cystic fibrosis and in $2 \%$ of those with chronic rhinosinusitis. ${ }^{4}$

Nasal polyps are among the common causes of chronic nasal congestion which may cause OSAS (obstructive sleep apnea syndrome) later and OSAS is associated with several cardiovascular diseases, such as congestive heart failure, hypertension, atrial fibrillation, nocturnal arrhythmias, stroke, pulmonary hypertension, and atherosclerosis. ${ }^{5,6}$ Mean platelet volume (MPV) is an important indicator of platelet activity. ${ }^{7}$

Studies in literature point out that inflammation related to nasal polyp is mostly dependent on eosinophils and their inflammatory products. Beside eosinophils, platelets may have a role in nasal polyp development. Platelets are involved in haemostasis, tissue repairing and inflammation. ${ }^{8}$ Although the relationship between nasal polyps and MPV was investigated in previous studies; we did not encounter any studies on the relationship between MPV, NLR and nasal polyps in Indian subjects.

\section{METHODS}

The cross-sectional observational study was done after institutional ethics committee permission. In this study we investigated CBC (complete blood count) parameters of the patients that consulted ENT clinic in a tertiary care teaching hospital, Haldia because of nasal polyp; between June 2015 to December 2015, who were ready to give informed consent for the above study. Patients with associated cardiovascular disorders and on antiplatelet therapy, smoking history or bleeding diathesis and aged over 65 and below 18 were excluded in the study. Patients with nasal polyp were not categorized according to the size or the side of the polyp. Control subjects were selected from age and sex matched persons from Haldia.

In both the groups, WBC (white blood cell count), RBC (red blood cell count), RDW (red blood cell distribution width), platelet count, MPV, PDW (platelet distribution width) and NLR parameters from the CBC results were compared between patients and controls. NLR was calculated as follows: NLR =Absolute neutrophil count/absolute lymphocyte count. CBC measurements were performed with an automated blood cell counter (Sysmex XE-2100; Sysmex, Kobe, Japan). All samples were run in duplicate, and the mean values of absolute neutrophil, platelet count, and lymphocyte count, MPV and NLR were compared between the study group and the control group. All of the investigations were statistically analyzed using SPSS program version 20 (IBM Corporation, NY, US). A two-tailed unpaired Student's t test was used to compare parametric conditions. A p value less than 0.05 was considered significant for all comparisons.

\section{RESULTS}

Out of 76 total cases of patients with nasal polyps, 30 [39.47\%] of the patients were females and 46 [60.52\%] were males, with a mean age of $41.08 \pm 16.5$ years. About 24 males and 18 females were included in the control group, with a mean age of $39.8 \pm 13.9$ years. There was no significant difference between the two groups regarding age and gender distribution as shown in Table 1.

Table 1: Distribution of age and values of WBC, HB, PLT and MPV in patients with nasal polyp and controls.

\begin{tabular}{|lll|l|}
\hline Characteristics & $\begin{array}{l}\text { Nasal Polyp } \\
\text { Mean } \pm \text { SD }\end{array}$ & $\begin{array}{l}\text { Control } \\
\text { Mean } \pm \text { SD }\end{array}$ & p value \\
\hline Age & $41.08 \pm 16.5$ & $39.8 \pm 13.9$ & 0.67 \\
\hline Gender & & & - \\
\hline Male & $46[60.52 \%]$ & $24[57.14 \%]$ & - \\
\hline Female & $30[39.47 \%]$ & $18[42.85 \%]$ & 0.5134 \\
\hline WBC & $6.89 \pm 1.33 \times 103 / \mu \mathrm{L}$ & $7.11 \pm 2.32 \times 103 / \mu \mathrm{L}$ & $0.0016^{*}$ \\
\hline Hb & $13.19 \pm 1.34 \mathrm{~g} / \mathrm{dL}$ & $14.1 \pm 1.67 \mathrm{~g} / \mathrm{dl}$ & $0.0001^{*}$ \\
\hline PLT & $232.38 \pm 39.97 \times 103 / \mu \mathrm{L}$ & $271.44 \pm 45.14 \times 103$ & $0.0001^{*}$ \\
\hline MPV & $9.11 \pm 1.08 \mathrm{fL}$ & $8.32 \pm 0.53 \mathrm{fL}$ & $0.0093^{*}$ \\
\hline PDW & $16.4 \pm 1.16 \mathrm{fL}$ & $15.78 \pm 1.32 \mathrm{fL}$ & 0.44 \\
\hline PCT & $0.22 \pm 0.068$ & $0.23 \pm 0.069$ & $0.0005^{*}$ \\
\hline NLR & $1.5 \pm 0.4$ & $1.8 \pm 0.5$ & ${ }^{2}$ \\
\hline
\end{tabular}

[MPV: Mean platelet volume; NLR: Neutrophil to lymphocyte ratio; WBC: White blood cell count; PLT: platelet; SD: standard deviation; PCT: Platelet crit; RDW: Red cell distribution width; PDW: Platelet distribution width; *: Statistically significant] 
Mean WBC values were $6.89 \pm 1.33 \times 103 / \mu \mathrm{L}$ in patients with NPs, vs. $7.11 \pm 2.32 \times 103 / \mu \mathrm{L}$ in the control group. There were no significant differences in WBC values between the two groups $(\mathrm{p}=0.51)$ as seen in Table 1 . Mean haemoglobin $(\mathrm{Hb})$ values were $13.19 \pm 1.34 \mathrm{~g} / \mathrm{dL}$ in patients with NPs, vs. $14.1 \pm 1.67 \mathrm{~g} / \mathrm{dl}$ in the control group. There were significant differences in $\mathrm{Hb}$ values between the two groups $(p=0.0016)$ as given in Table 1 . Mean MPV values were $9.11 \pm 1.08 \mathrm{fL}$ in patients with NPs, vs. $8.32 \pm 0.53 \mathrm{fL}$ in the control group. There were significant differences in MPV values between two groups $(\mathrm{p}=0.0001)$ as in Table 1. Mean PLT values were $232.38 \pm 39.97 \times 103 / \mu \mathrm{L}$ in patients with NPs, vs. $271.44 \pm 45.14 \times 103$ in the control group.

There was significant differences in PLT values between the two groups $(p=0.0001)$ as in Table 1 . PDW values were $16.4 \pm 1.16 \mathrm{fL}$ in patients with NPs, vs. $15.78 \pm 1.32$ $\mathrm{fL}$ in the control group. There were significant differences in PDW values between the two groups $(\mathrm{p}=0.0093)$ as presented in Table 1. PCT values were $0.22 \pm 0.068$ in patients with NPs, vs. $0.23 \pm 0.069$ in the control group. There was no significant difference in PCT values between the two groups $(p=0.44)$ as tabulated in Table 1.

NPs in 49 [64.47\%] of patients were bilateral $(n=76)$ and 27 [35.52\%] in patients were unilateral. In men, 29 [63.04\%] were bilateral $(n=46)$, and 17 [36.95\%] were unilateral. In women, 17 [56.6\%] were bilateral $(\mathrm{n}=30)$, and 13 [43.33\%] were unilateral. MPV was higher in nasal polyp patients, whereas platelet count was higher in controls as in Table 1. The difference was significant for the mean absolute neutrophil, platelet count, and lymphocyte counts, NLR, PDW and MPV values between the study group and the control group as depicted in Table 1 .

\section{DISCUSSION}

Nasal polyps diagnosed clinically are not always of inflammatory origin. A variety of non-neoplastic and neoplastic conditions can present as nasal polyps. Nonneoplastic conditions such as Wegener's granulomatosis, sarcoidosis, rhinosporidiosis; benign neoplastic conditions such as inverted papilloma, capillary hemangioma (pyogenic granuloma), angiofibroma, chondroma, plasmacytoma, meningioma, leiomyoma, schwannoma, meningoencephalocele, pituitary adenoma, paraganglioma; and malignant conditions such as squamous cell carcinoma, adenocarcinoma, malignant melanoma, chordoma, olfactory neuroblastoma, rhabdomyosarcoma and adenoid cystic carcinoma can present as nasal polyps. ${ }^{9-11}$

Nevertheless, the majority of nasal polyps result as a consequence of chronic mucosal inflammation, and inflammatory polyps are the commonest of all polypoidal lesions in the nose presenting as nasal polyps and are synonymous with nasal polyps. ${ }^{11}$
Platelet activation and aggregation is closely associated with cardiovascular complications. In many studies, platelet activation and aggregation have been reported to increase in patients with OSAS. ${ }^{12,13}$ Mean platelet volume (MPV) is a parameter used as an indicator of platelet activation. Larger platelets are more reactive than normal-sized ones and have higher prothrombotic potentials. Mean platelet volume is considered as a marker of atherosclerosis. ${ }^{14-17}$

In previous studies, MPV has been reported to increase in adult cerebrovascular and cardiovascular conditions such as hypertension, unstable angina pectoris, myocardial infarction and stroke. ${ }^{16}$ It has been shown that elevated MPV levels could be associated with the prognoses of these diseases. ${ }^{16}$

CBC is a widely used blood test that provides useful information about patient general health and inflammatory status. High neutrophil and platelet counts reflect inflammation, whereas a low lymphocyte count reflects general stress and poor health. ${ }^{17}$ NLR is a practical, cost-effective and valuable marker of inflammatory state that can easily be calculated from CBC tests. ${ }^{18}$ It has been found to be a valuable predictor of poor prognosis and long-term mortality in oncological patients, in coronary artery disease, end-stage renal disease and inflammatory diseases such as ulcerative collitis and appendicitis. ${ }^{19-24}$

When WBC parameter was examined in the current study, there were no significant differences between the patients and the controls in any of the three groups. In the study by Aktas et al and Sagit et al WBC parameter was not different in patients and controls again and both of these studies are supporting our results. ${ }^{8,24}$

"RDW" is a numerical measure of the size variability of circulating erythrocytes. ${ }^{25}$ Disorders related to ineffective erythropoiesis or increased red blood cell destruction cause heterogeneity in size and a higher RDW. ${ }^{26,27} \mathrm{RDW}$ has been reported as an independent predictor of adverse outcomes in the general population and is believed to be associated with cardiovascular morbidity and mortality in patients with a previous myocardial infarction. ${ }^{28-30}$

Platelet count in the studies of Aktas et al and Sagit et al was not different between patients with nasal polyps and controls, however unlike these studies; we have observed that the platelet count was significantly lower in patients than in controls group. ${ }^{8,24}$ A study by Ulu et al in which the platelet count was investigated in patients with septal deviation which frequently causes chronic nasal congestion reported that the platelet count was lower in patients than in controls supporting our results. ${ }^{31}$

Increased platelet activity is associated with increased platelet volume, which can be measured by larger mean platelet volume (MPV) and platelet distribution width (PDW). Large platelets are more adhesive and tend to 
aggregate more than smaller ones. ${ }^{32}$ This increase in platelet volume increases the tendency for coronary thrombus formation in acute coronary syndrome patients. $^{33}$ MPV is also used as a marker in atherosclerosis. ${ }^{34,35}$ Many clinical studies have shown that increased MPV in patients with OSAS is associated with increased risk of atherosclerosis and cardiac disorders. ${ }^{36}$

In our study, PDW scores were different between patients with nasal polyps and controls. The study by Sagit et al which investigates the relationship between nasal polyps and PDW did not report a difference between the patients and the controls, further not supporting our data. ${ }^{24}$

When MPV scores were examined in the current study, significantly higher MPV scores in patients with nasal polyps than in controls. In literature, the study by Sagit et al directly investigating the relationship between nasal polyps and MPV reported a significantly higher MPV score in patients than in controls, whereas the study by Aktas et al found an MPV score significantly lower in patients than in controls. ${ }^{8,24}$ Our study, especially the significant difference, supports the study by Sagit et al. ${ }^{24}$ Other studies including patients with OSAS have reported significantly higher MPV scores in patients than in controls. ${ }^{37,38}$ Again, the study by Ulu et al on patients with septal deviation causing chronic nasal congestion reported significantly higher MPV scores in patients than in controls. ${ }^{31}$ The study by Cengiz et al on adenoid hypertrophy patients (which causes pediatric OSAS) reported lower MPV scores in patients. ${ }^{17}$ All these results show that the relationship between MPV, nasal congestion and OSAS is not clear yet.

The neutrophil-to-lymphocyte ratio (NLR) and plateletto-lymphocyte ratio (PLR) have been defined as novel markers of inflammation and thrombotic events which can be easily measured from the complete blood cell count (CBC). ${ }^{39}$ Sudden sensorineural hearing loss, Bell's palsy and vestibular neuritis are certain pathological conditions that have been found to be related to NLR and PLR in otolaryngological practice. ${ }^{40-42}$ Mean platelet volume (MPV) is a blood marker related to function and activation of platelets. ${ }^{43}$

A study on patients with stroke reported that NLR increase and CRP ( $\mathrm{C}$ reactive protein) which is an inflammation marker are significantly correlated. ${ }^{44}$ The study by Gokhan et al showed NLR scores increase significantly in ischemic and hemorrhagic stroke. ${ }^{45}$ Because OSAS and cardiovascular diseases are frequently observed in patients with nasal polyps in which structure of neutrophil and lymphocytes play an important role, we have chosen to investigate the relationship between nasal polyps and NLR scores. In our study, we observed that the NLR scores were significantly lower in patients with nasal polyps than controls.
Mean platelet volume has emerged as a marker of inflammation that is routinely examined in CBC tests. A high level of MPV is indicative of increased platelet activity, which causes more intense inflammation. ${ }^{15}$ An increased level of MPV was found to be related to various pathological conditions, including cardiovascular and cerebrovascular disorders, and deep venous thrombosis. ${ }^{46-48}$ MPV was also investigated in some studies related to otolaryngological pathologies. Poorey et al reported an increased level of MPV due to chronic nasal obstruction in patients with deviated nasal septum. ${ }^{49}$

\section{CONCLUSION}

Platelet count and NLR were significantly lower in patients than the controls, whereas MPV was significantly higher in nasal polyp patients. We believe these parameters will have increasing clinical use in the future as more information is gathered from large-scale prospective studies that will investigate the effect of hematological parameters on treatment options and prognosis.

\section{Funding: No funding sources}

Conflict of interest: None declared

Ethical approval: The study was approved by the Institutional Ethics Committee

\section{REFERENCES}

1. Newton JR, Ah-See KW. A review of nasal polyposis. Ther Clin Risk Manag. 2008;4(2):507-12.

2. Kahveci OK, Duran A, Miman MC. Our histopathological results for intranasal masses; retrospective study of 6 years. J Clin Anal Med 2012;3(3):289-92.

3. Bachert C, Gevaert P, Holtappels G, Cuvelier C, van Cauwenberge P. Nasal polyposis: from cytokines to growth. Am J Rhinol 2000;14:279-90.

4. Stamm AC, Draf W. Microendoscopic Surgery of Paranasal Sinuses and the Skull Base. New York: Springer; 2000.

5. Dempsey JA, Veasey SC, Morgan BJ, O'Donnell CP. Pathophysiology of sleep apnea. Physiol Rev 2010;90:47-112.

6. Drager LF, Togeiro SM, Polotsky VY, LorenziFilho G. Obstructive sleep apnea: a cardiometabolic risk in obesity and the metabolic syndrome. J Am Coll Cardiol. 2013;62:569-76.

7. Karnath S, Blann AD, Lip GY. Platelet activation: assessment and quantification. Eur Heart J. 2001;22:1561-71.

8. Aktas G, Sit M, Tekce H, Alcelik A, Savli H, Simsek T, et al. Mean platelet volume in nasal polyps. West Indian Med J. 2013;62(6):515-8.

9. Diamantopoulos II, Jones NS, Lowe J. All nasal polyps need histological examination: an auditbased appraisal of clinical practice. J Laryngol Otol. 2000;114:755-9. 
10. Dasgupta A, Ghosh RN, Mukherjee C. Nasal polyps: histopathologic spectrum. Indian J Otolaryngol Head Neck Surg. 1997;49:32-7.

11. Shulbha VS, Dayananda BS. Clinicopathological study of nasal polyps with special reference to mast cells in inflammatory polyps. Basic Appl Pathol. 2012;5:59-62.

12. Kanbay A, Tutar N, Kaya E, Buyukoglan H, Ozdogan N, Oymak FS, et al. Mean platelet volume in patients with obstructive sleep apnea syndrome and its relationship with cardiovascular diseases. Blood Coagul Fibrinolysis. 2013;24:532-6.

13. Karakaş MS, Altekin RE, Baktır AO, Küçük M, Cilli A, Yalçınkaya S. Association between mean platelet volume and severity of disease in patients with obstructive sleep apnea syndrome without risk factors for cardiovascular disease. Turk Kardiyol Dern Ars. 2013;41:14-20.

14. Chu SG, Becker RC, Berger PB, Bhatt DL, Eikelboom JW, Konkle B, et al. Mean platelet volume as a predictor of cardiovascular risk: a systematic review and metaanalysis. J Thromb Haemost. 2010;8:148-56.

15. Gasparyan AY, Ayvazyan L, Mikhailidis DP, Kitas GD. Mean platelet volume: a link between thrombosis and inflammation? Curr Pharm Des. 2011; 17:47-58.

16. Vizioli L, Muscari S, Muscari A. The relationship of mean platelet volume with the risk and prognosis of cardiovascular diseases. Int $\mathrm{J}$ Clin Pract. 2009;63:1509-15.

17. Cengiz C, Erhan Y, Murat T, Ercan A, Ibrahim S, Ihsan $\mathrm{G}$, et al. Values of mean platelet volume in patients with chronic tonsillitis and adenoid hypertrophy. Pak J Med Sci. 2013;29:569-72.

18. Tefferi A, Hanson CA, Inwards DJ. How to interpret and pursue an abnormal complete blood cell count in adults. Mayo Clin Proc. 2005;80:92336.

19. Azab B, Bhatt VR, Phookan J, Murukutla S, Kohn $\mathrm{N}$, Terjanian $\mathrm{T}$, et al. Usefulness of the neutrophil to lymphocyte ratio in predicting short- and long-term mortality in breast cancer patients. Ann Surg Oncol. 2012;19:217-24.

20. Jung MR, Park YK, Jeong O, Seon JW, Ryu SY, Kim DY, et al. Elevated preoperative neutrophil to lymphocyte ratio predicts poor survival following resection in late stage gastric cancer. J Surg Oncol. 2011;104:504-10.

21. Uthamalingam S, Patvardhan EA, Subramanian S, Ahmed W, Martin W, Daley M, et al. Utility of the neutrophil to lymphocyte ratio in predicting longterm outcomes in acute decompensated heart failure. Am J Cardiol. 2011;107:433-8.

22. Bayram A, Yaflar M, Doan M, Güneri E, Özcan. Assessment of neutrophil-to-lymphocyte ratio, platelet-to-lymphocyte ratio and mean platelet volume in patients with tinnitus. ENT Updates. 2015;5(3):103-6.
23. Turkmen K, Guney I, Yerlikaya FH, Tonbul HZ. The relationship between neutrophil-to-lymphocyte ratio and inflammation in end-stage renal disease patients. Ren Fail. 2012;34:155-9.

24. Sagit M, Cetinkaya S, Dogan M, Bayram A, Vurdem UE, et al. Mean platelet volume in patients with nasal polyposis. B-ENT. 2012;8:269-72.

25. Torun S, Tunc BD, Suvak B, Yildiz H, Tas A, Sayilir A, et al. Assessment of neutrophillymphocyte ratio in ulcerative colitis: a promising marker in predicting disease severity. Clin Res Hepatol Gastroenterol. 2012;36:491-7.

26. Romero AJ, Carbia CD, Ceballo MF, Diaz NB. Red cell distribution width (RDW): its use in the characterization of microcytic and hypochromic anemias. Medicina (B Aires). 1999;59:17-22.

27. Tonelli M, Sacks F, Arnold M, Moye L, Davis B, Pfeffer M. for the Cholesterol and Recurrent Events (CARE) Trial Investigators. Relation between red blood cell distribution width and cardiovascular event rate in people with coronary disease. Circulation. 2008;117:163-8.

28. Perlstein TS, Weuve J, Pfeffer MA, Beckman JA. Red blood cell distribution width and mortality risk in a community-based prospective cohort. Arch Intern Med. 2009;169:588-94.

29. Felker GM, Allen LA, Pocock SJ, Shaw LK, McMurray JJ, Pfeffer MA, et al. Red cell distribution width as a novel prognostic marker in heart failure: data from the CHARM Program and the Duke Databank. J Am Coll Cardiol. 2007;50:407.

30. Akil F, Yollu U, Turgut F, Ayral1 M. The Relationship Between Nasal Polyps, Mean Platelet Volume, Neutrophile/Lymphocyte Ratio and Platelet Count. Otolaryngol. 2016;6(4):140

31. Ulu S, Ulu MS, Bucak A, Kahveci OK, Yucedag F, et al. Evaluating the relationship between nasal obstruction and mean platelet volume by using acoustic rhinometry in patients with septum deviation. Rhinol. 2013;51:249-52.

32. Schoene NW. Design criteria: tests used to assess platelet function. Am J Clin Nutr. 1997;65:1665-85.

33. Huczek Z, Filipiak KJ, Kochman J, Michalak M, Roik M, et al. Baseline platelet size is increased in patients with acute coronary syndromes developing early stent thrombosis and predicts future residual platelet reactivity. A case-control study. Thromb Res. 2010;125:406-12.

34. Gigante J. Tonsillectomy and adenoidectomy. Pediatr Rev. 2005;26:199-202.

35. Drager LF, Polotsky VY, Lorenzi-Filho G. Obstructive sleep apnea: an emerging risk factor for atherosclerosis. Chest. 2011;140:534-42.

36. Li RC, Haribabu B, Mathis SP, Kim J, Gozal D. Leukotriene B4 receptor-1 mediates intermittent hypoxia induced atherogenesis. Am J Respir Crit Care Med. 2011;184:124-31.

37. Kent BD, Ryan S, McNicholas WT. Obstructive sleep apnea and inflammation: relationship to 
cardiovascular co-morbidity. Respir Physiol Neurobiol. 2011;178:475-81.

38. Kondo Y, Kuwahira I, Shimizu M, Nagai A, Iwamoto T, et al. Significant relationship between platelet activation and apnea-hypopnea index in patients with obstructive sleep apnea syndrome. Tokai J Exp Clin Med. 2011;36:79-83.

39. Ferroni P, Riondino S, Formica V, Cereda V, Tosetto L, Farina FL, et al. Venous thromboembolism risk prediction in ambulatory cancer patients: clinical significance of plate/lymphocyte ratio and platelet/lymphocyte ratio. Int J Cancer. 2015;136:1234-40.

40. Chung JH, Lim J, Jeong JH, Kim KR, Park CW, Lee SH. The significance of neutrophil to lymphocyte ratio and platelet to lymphocyte ratio in vestibular neuritis. Laryngoscope. 2015;125:25761.

41. Bucak A, Ulu S, Oruc S, Yucedag F, Tekin MS, Karakaya F, et al. Neutrophil-to-lymphocyte ratio as a novel-potential marker for predicting prognosis of Bell palsy. Laryngoscope. 2014;124:1678-81.

42. Seo YJ, Jeong JH, Choi JY, Moon IS. Neutrophilto-lymphocyte ratio and platelet-to-lymphocyte ratio: novel markers for diagnosis and prognosis in patients with idiopathic sudden sensorineural hearing loss. Dis Markers. 2014;2014:702807.

43. Karli R, Alacam H, Unal R, Kucuk H, Aksoy A, Ayhan E. Mean platelet volume: is it a predictive parameter in the diagnosis of sudden sensorineural hearing loss? Indian J Otolaryngol Head Neck Surg. 2013;65:350-3.

44. Lee JH, Kwon KY, Yoon SY, Kim HS, Lim CS. Characteristics of platelet indices, neutrophil-tolymphocyte ratio and erythrocyte sedimentation rate compared with $\mathrm{C}$ reactive protein in patients with cerebral infarction: a retrospective analysis of comparing haematological parameters and $\mathrm{C}$ reactive protein. BMJ Open. 2014;4:e006275.

45. Gökhan S, Ozhasenekler A, Mansur DH, Akil E, Ustündag M, et al. Neutrophil lymphocyte ratios in stroke subtypes and transient ischemic attack. Eur Rev Med Pharmacol Sci. 2013;17:653-7.

46. Verdoia M, Camaro C, Barbieri L, et al. Mean platelet volume and the risk of peri-procedural myocardial infarction in patients undergoing coronary angioplasty. Atherosclerosis 2013;228:136-41.

47. Greisenegger S, Endler G, Hsieh K, Tentschert S, Mannhalter C, Lalouschek W. Is elevated mean platelet volume associated with a worse outcome in patients with acute ischemic cerebrovascular events? Stroke. 2004;35:1688-91.

48. Han JS, Park TS, Cho SY, Joh JH, Ahn HJ. Increased mean platelet volume and mean platelet volume/platelet count ratio in Korean patients with deep vein thrombosis. Platelets. 2013;24:590-3.

49. Poorey VK, Thakur P. Effect of deviated nasal septum on mean platelet volume: a prospective study. Indian J Otolaryngol Head Neck Surg. 2014;66:437.

Cite this article as: Sharma M, Raman S, Ray B, Bagga RV, Sahu RK, De S. Study the relationship between nasal polyps, platelet count, mean platelet volume, neutrophil/lymphocyte ratio in patients attending otolaryngology OPD in a tertiary care teaching hospital, West Bengal. Int J Otorhinolaryngol Head Neck Surg 2017;3:228-33. 